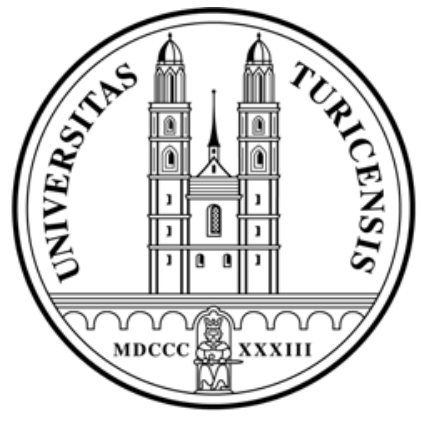

Institute for Empirical Research in Economics

University of Zurich

Working Paper Series

ISSN 1424-0459

Working Paper No. 477

Malthus Was Right:

New Evidence from a Time-Varying VAR

Alexander Rathke and Samad Sarferaz

February 2010 


\title{
Malthus Was Right: \\ New Evidence from a Time-Varying VAR*
}

\author{
Alexander Rathke $\quad$ Samad Sarferaz \\ University of Zurich $\quad$ ETH Zurich
}

February 2010

\begin{abstract}
Although Unified Growth Theory presumes the existence of the Maltusian mechanism in pre-industrial England recent empirical studies challenged this assumption. This paper studies the interaction of vital rates and real wages in the period from 1540 to 1870 in England. We employ time-varying VARs, an approach which addresses potential shortcomings such as parameter instability and declining volatilities in the previous literature. In contrast to recent studies, the main Malthusian mechanisms - the preventive and the positive check - were both at work until the mid-19th century. The preventive check was decreasing and the positive check increasing in importance. Most remarkably, the positive check dominated after the 1750s. The results indicate that instead of disappearing before the advent of the industrial revolution, the Malthusian mechanism rather changed its face over time.
\end{abstract}

JEL: C32, J13, N13, O11

Keywords: Industrial Revolution, Malthusian trap, Time-Varying Vector Autoregression, Unified Growth Theory

${ }^{*}$ We are grateful to Julia Casutt-Schneeberger, Oded Galor, John Komlos, Ronald Lee, Jim Malley, Ulrich Pfister, Wolfgang Reichmuth, Albrecht Ritschl, Tobias Straumann, Hans-Joachim Voth, Ulrich Woitek and seminar participants at the Humboldt University, University of Münster, and Bodensee Symposium for very helpful comments.

${ }^{\dagger}$ Institute for Empirical Research in Economics, University of Zurich, Winterthurerstr. 30, CH - 8006 Zurich; email: rathke@iew.uzh.ch.

${ }^{\ddagger}$ Konjunkturforschungsstelle (KOF), Weinbergstrasse 35, CH - 8092 Zurich; email: sarferaz@kof.ethz.ch. 


\section{Introduction}

Economic growth as it is observed in modern industrialized societies is a relatively young phenomenon. For most of the time, economic development stagnated with hardly growing population and relatively stable real wages. Not until the sectoral shift from agriculture to industry did this stasis come to an end, marking the beginning of one of the most important events in world economic history, the industrial revolution.

For the stagnating phase, Thomas Robert Malthus provided an economicdemographic framework, which laid the foundation for the so-called "Malthusian" theory (Malthus, 1798). The Malthusian framework can be understood as a self-equilibrating system of population and economic activity in which the population level is stable at a subsistence wage level. Three assumptions are crucial to perpetuate the equilibrium. First, real wages are a decreasing function of population due to the existence of the fixed factor land. In other words, the production function exhibits decreasing returns on labor. Second, fertility positively depends on real wages (i.e. preventive check), as e.g. increasing wages allow for a higher number of marriages. Third, mortality negatively depends on real wages (i.e. positive check). A decrease in wages causes malnutrition and deteriorating health conditions, which leads to higher mortality rates.

Devising a framework that encompasses the transition from a stagnant Malthusian to a prospering economy is the task of the unified growth theory. Many different aspects have been emphasized so far, e.g. human capital, demography, technological progress, or the influence of institutions. ${ }^{1}$ The prevalent explanation among economists for the transition from stagnation to growth stresses the role of human capital accumulation, technology and population

\footnotetext{
${ }^{1}$ An extensive overview can be found in Galor (2005). Recent contributions include Cervellati and Sunde (2005, 2006); Galor (2009); Galor and Moav (2002); Hansen and Prescott (2002); Lucas (2002); Jones (2001); Tamura (2002) and Lagerlöf (2003, 2006). For earlier contributions, see Artzrouni and Komlos (1985); Komlos and Artzrouni (1990) and Kremer (1993).
} 
dynamics. For example, in Galor and Weil (2000) population growth accelerates the rate of technological change making human capital more valuable. A virtuous cycle between technological progress and human capital formation ensues, as parents start to substitute "quantity for quality", i.e. reducing the number of children while increasing their education. First, increasing income allows households to have more offspring; later, the substitution effect dominates and fertility declines. Other studies emphasize the role of mortality in the transition. For example, Cervellati and Sunde (2005) assume that rising life expectancy increases the incentive to invest in human capital. This can also result in a self-reinforcing circle of better technology, higher life expectancy, and human capital formation. Irrespective of the focus of the explanation it is important to be clear about the stylized facts which the model should be able to replicate. ${ }^{2}$

Yet, for late pre-industrial England, empirical evidence has recently challenged the existence of the Malthusian model. ${ }^{3}$ Lee and Anderson (2002) apply a structural model with time-varying coefficients to data on England for the period from 1540 to 1870 . While their results still assign a minor role to the preventive check, the positive check cannot be found at all. The feedback effect of population on real wages has also been found to be weaker than in earlier studies. Hence, they conclude that the Malthusian framework was hardly at work during the pre-industrial period. Nicolini (2007) uses vector autoregression (VAR) techniques focusing on the short-run relationship between death and birth rates and real wages. Using this framework, he tests the Malthusian hypothesis for the period of 1540 to $1840^{4}$ and finds that the positive check appeared only until the 17th century, while the preventive check disappeared before 1740. Crafts and Mills (2009) redo the analysis conducted by Lee and Anderson (2002) and Nicolini (2007), using

\footnotetext{
${ }^{2} \mathrm{~A}$ discussion of unified growth theories and a historical appraisal can be found in Mokyr and Voth (2007) and Broadberry (2007).

${ }^{3}$ Ashraf and Galor (2008) provide cross country evidence suggesting that the Malthusian mechanisms were strong for the earlier time period 1-1500.

${ }^{4}$ Møller and Sharp (2008) also use a VAR, but focus on the long-run relationship between demographic variables and real wages, using cointegration analysis.
} 
a new wage series compiled by Clark (2005). Like Lee and Anderson (2002) and Nicolini (2007), they also come to the conclusion that the Malthusian equilibrium did not exist in late pre-industrial England. Nicolini therefore asserts that "perhaps the world before Malthus was not so Malthusian after all" (Nicolini, 2007, p. 116).

However, there are several potential shortcomings concerning the literature which disproves the Malthusian hypothesis for pre-industrial England. The first is how they deal with volatility changes in the magnitudes analyzed. As can be seen in Figure 1, the declining volatilities of birth and death rate series are apparent. Nicolini (2007) models this feature indirectly by arbitrarily dividing his sample into sub-samples of hundred years. Lee and Anderson (2002) also ignore this point: they leave the variances fixed, but allow for time variation in the parameters. A second and obvious issue is the timevarying relationship between birth and death rates and real wages, as all studies work with data covering about three centuries. Nicolini (2007) again uses sub-samples to capture time variation in the coefficients of his model. However, this implies that information based on the entire sample is lost and that the results depend on the arbitrary choice of the sub-samples. As already mentioned above, Lee and Anderson (2002) use time-varying coefficients in their state space model, but the crucial parameters connecting birth rates and death rates to wages are held fixed. Thus, to test the Malthusian hypothesis, a model capturing both time variation in the coefficients and variances is required. To the best of our knowledge, this has not been conducted for any empirical study on economic and demographic interactions.

This paper uses a VAR with time-varying coefficients and stochastic volatilities, as described in Primiceri (2005). This approach enables the shortcomings mentioned above to be overcome, where the transition from the Malthusian to an industrialized economy is modeled explicitly, exploiting the information included in the whole sample. Instead of splitting the sample into several sub-samples, the time-varying coefficients capture the change in the propagation mechanism. The time variation in the parameters enables 
the exact dating of the transition. The time-varying variances capture the change in the impact and nature of the shocks, enabling us to model the apparent decline in volatility (Figure 1). Thus it is possible to address the potential shortcomings of the empirical literature by explicitly modeling the underlying time variation of the relationship between the variables of the model and their variances.

The model is applied to data on birth and death rates as well as on real wages for England in the period from 1540 to 1870. This observation period captures the transition from the Malthusian to an industrialized economy. The time-varying VAR analysis reveals that the preventive check was strong up until the mid-18th century and that the positive check was dominant in the period between 1750 and 1850. This result is in sharp contrast to the recent literature on the Malthusian framework with respect to the late preindustrial England. While in the beginning of the observation period the accumulated impact after ten years is 10 percent, it is halved by the beginning of the 19th century. The Malthusian positive check has an accumulated impact of 5 percent at the beginning of our sample, which is doubled by the mid-19th century. For the feedback effect of mortality on real wages, we find an overall downward trend over the whole sample. Moreover, the apparent decline of volatility in the birth and death rate series is confirmed by our stochastic volatility results. The results imply that, instead of disappearing, the Malthusian framework changed over time. The appearance of the positive check in the period between 1750 and 1850 is probably our most striking result. Even though it is grounded in the historical literature on the industrial revolution, it has so far not been found in the econometric studies.

The rest of the paper is structured as follows. The next section describes the time-varying VAR model. Section 3 discusses the data used. The prior assumptions are revealed in Section 4. The results are presented in Section 5 and finally Section 6 concludes. 


\section{Time-Varying Vector Autoregression}

The following section describes the model proposed by Primiceri (2005), which is closely related to Cogley and Sargent (2005). The model allows for time-varying coefficients and volatilities, providing extrem flexibility with a parsimonious specification. A minor extension is that we also allow for exogenous regressors.

Consider the following VAR model with time-varying coefficients and stochastic volatilities

$$
\mathbf{y}_{t}=\mathbf{C}_{t} \mathbf{x}_{t}+\sum_{j=1}^{p} \mathbf{A}_{j, t} \mathbf{y}_{t-j}+\mathbf{u}_{t}
$$

where $\mathbf{y}_{t}$ is a $n \times 1$ vector of endogenous time series, $\mathbf{C}_{t}$ is a time-varying $n \times z$ matrix of parameters including a constant, $\mathbf{x}_{t}$ is a $z \times 1$ vector of exogenous variables and $\mathbf{A}_{j, t}$ are $p$ time-varying $n \times n$ parameter matrices. ${ }^{5}$ Rewriting the model in matrix form yields

$$
\begin{aligned}
& \mathbf{y}_{t}=\left(\begin{array}{llll}
\mathbf{C}_{t} & \mathbf{A}_{1, t} & \ldots & \mathbf{A}_{p, t}
\end{array}\right)\left(\begin{array}{c}
\mathbf{x}_{t} \\
\mathbf{y}_{t-1} \\
\vdots \\
\mathbf{y}_{t-p}
\end{array}\right)+\mathbf{u}_{t}, \\
& \mathbf{y}_{t}=\mathbf{A}_{t} \mathbf{z}_{t-1}+\mathbf{u}_{t} .
\end{aligned}
$$

Vectorizing both sides gives

$$
\mathbf{y}_{t}=\left(\mathbf{Z}_{t-1}^{\prime} \otimes \mathbf{I}_{n}\right) \mathbf{a}_{t}+\mathbf{u}_{t}
$$

where $\mathbf{a}_{t}=\operatorname{vec}\left[\begin{array}{llll}\mathbf{C}_{t} & \mathbf{A}_{1, t} \ldots & \mathbf{A}_{p, t}\end{array}\right] .{ }^{6}$ The errors $\mathbf{u}_{t}$ are assumed to be normally distributed with zero mean and time-varying covariance matrix $\boldsymbol{\Omega}_{t}$. The error

\footnotetext{
${ }^{5}$ The following notation is used throughout: subscripts denote period $t$ values of a variable (or vector of variables), and superscripts denote the history of a variable (or vector of variables) up to time $t$, e.g. $\mathbf{d}^{t}=\left[\begin{array}{llll}\mathbf{d}_{1} & \mathbf{d}_{2} & \ldots & \mathbf{d}_{t}\end{array}\right]$.

${ }^{6}$ Note that, in contrast to Primiceri (2005), the matrix is vectorized along the column dimension.
} 
term is structured as follows

$$
\mathbf{u}_{t}=\mathbf{B}_{t}^{-1} \boldsymbol{\Sigma}_{t} \boldsymbol{\epsilon}_{t}
$$

where $\mathbf{B}_{t}$ is a lower triangular matrix with ones on the main diagonal, $\boldsymbol{\Sigma}_{t}$ is a diagonal matrix, and $\boldsymbol{\epsilon}_{t}$ is assumed to be distributed as standard normal:

$$
\mathbf{B}_{t}=\left(\begin{array}{cccc}
1 & 0 & \ldots & 0 \\
b_{21, t} & 1 & \ddots & \vdots \\
\vdots & \ddots & \ddots & 0 \\
b_{n 1, t} & \ldots & b_{n(n-1), t} & 1
\end{array}\right) \text { and } \boldsymbol{\Sigma}_{t}=\left(\begin{array}{cccc}
\sigma_{1, t} & 0 & \ldots & 0 \\
0 & \sigma_{2, t} & \ddots & \vdots \\
\vdots & \ddots & \ddots & 0 \\
0 & \ldots & 0 & \sigma_{n, t}
\end{array}\right)
$$

The vectors $\mathbf{b}_{t}=\left[b_{21, t},\left(b_{31, t} b_{32, t}\right), \ldots,\left(b_{n 1, t} \ldots b_{n(n-1), t}\right)\right]^{\prime}$ are the equationwise stacked free parameters of $\mathbf{B}_{t}$, and $\mathbf{h}_{t}=\log \left(\operatorname{diag}\left(\boldsymbol{\Sigma}_{t}\right)\right)$. The laws of motion of the parameters are assumed to be independent random walks,

$$
\begin{aligned}
\mathbf{a}_{t} & =\mathbf{a}_{t-1}+\boldsymbol{\nu}_{t}, \\
\mathbf{b}_{t} & =\mathbf{b}_{t-1}+\boldsymbol{\zeta}_{t}, \\
\mathbf{h}_{t} & =\mathbf{h}_{t-1}+\boldsymbol{\eta}_{t} .
\end{aligned}
$$

The variance-covariance matrix of the innovations is block diagonal:

$$
\left(\begin{array}{c}
\boldsymbol{\epsilon}_{t} \\
\boldsymbol{\nu}_{t} \\
\boldsymbol{\zeta}_{t} \\
\boldsymbol{\eta}_{t}
\end{array}\right) \sim N(\mathbf{0}, \mathbf{V}), \mathbf{V}=\left(\begin{array}{cccc}
\mathbf{I}_{n} & \mathbf{0} & \mathbf{0} & \mathbf{0} \\
\mathbf{0} & \mathbf{Q} & \mathbf{0} & \mathbf{0} \\
\mathbf{0} & \mathbf{0} & \mathbf{S} & \mathbf{0} \\
\mathbf{0} & \mathbf{0} & \mathbf{0} & \mathbf{W}
\end{array}\right)
$$

For simplicity, it is also assumed that the matrix $\mathbf{S}$ is also block-diagonal with respect to the parameter blocks belonging to each equation. ${ }^{7}$

\footnotetext{
${ }^{7}$ See Primiceri (2005) for a discussion about relaxing this assumption.
} 
Figure 1: Demographic and economic data series: 1541 to 1870

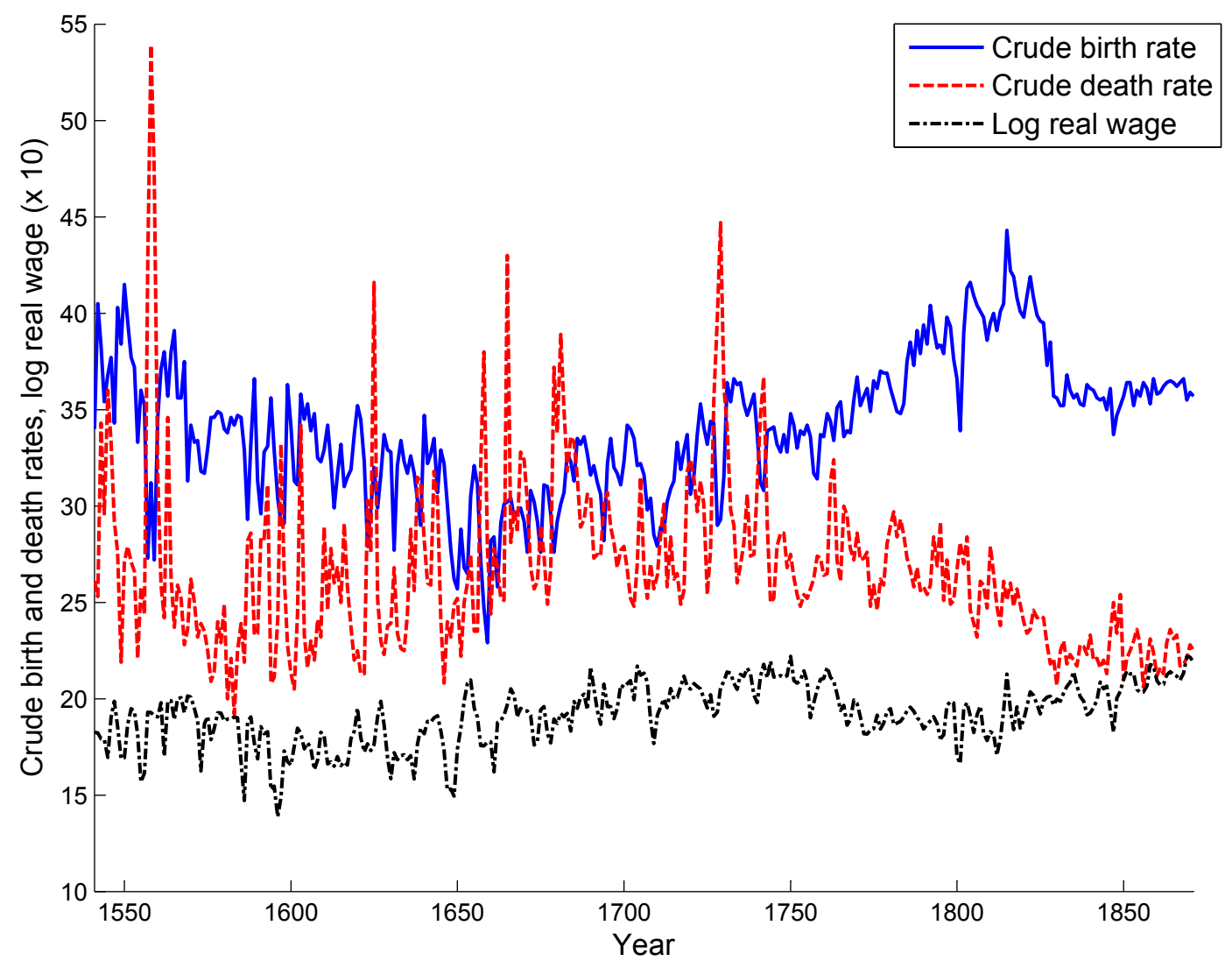

\section{Data}

For the empirical analysis, we use well known data on the following three variables: the crude birth and death rates $^{8}$ and a real wage index. The demographic variables were compiled by Wrigley and Schofield (1981) and the wage series is taken from Allen (2001). For the analysis, annual data covering the period from 1541 to 1870 are utilized. The raw data series are depicted in Figure 1.

The structural VAR approach usually has the disadvantage that the empiri-

${ }^{8}$ The conventional unit is number of births (deaths) per one thousand people. 
cal results may depend on the ordering of the variables in the system due to the recursive identification scheme. ${ }^{9}$ Fortunately, this identification strategy fits very well in our setting since the ordering of the demographic variables is predetermined by biology (Nicolini, 2007). The time interval between the decision to have a child and conception is on average over seven months (Bongaarts, 1978). Adding this to the nine-month of pregnancy, the endogenous reaction of the birth rate is delayed by over a year. As a result, it is safe to order the crude birth rate first. The crude death rate is ordered second and the real wage last. This allows us to compare our results to those of Nicolini (2007) and Reichmuth (2008) who chose the same ordering. Thus, the following data vector is used for the VAR:

$$
\mathbf{y}_{t}=\left[C B R_{t}, C D R_{t}, w_{t}\right]^{\prime}
$$

where $C B R$ denotes the crude birth rate, $C D R$ the crude death rate, and $w$ the log of the real wage.

\section{Priors}

We follow Primiceri (2005) and use the sample from 1541 to 1599 to find values for the priors. We estimate a time-invariant VAR model by OLS and use the point estimates to calibrate some of the prior distributions. The remaining prior distributions are also chosen in a manner similar to Primiceri (2005). Note that we work with annual instead of quarterly data and investigate the relationship between demographic and economic variables instead of analyzing monetary policy. Hence, we use somewhat tighter priors on the innovations of the time-varying parameters to ensure a smooth behavior of these parameters. This reflects our belief that the relationship between the demographic and economic variables does not change from year to year, but

\footnotetext{
${ }^{9}$ Sticking to the recursive identification scheme is not necessary. Once the matrix $\boldsymbol{\Omega}_{t}=\mathbf{B}_{t}^{-1} \boldsymbol{\Sigma}_{t} \boldsymbol{\Sigma}_{t}^{\prime} \mathbf{B}_{t}^{-1^{\prime}}$ is obtained, any decomposition of $\boldsymbol{\Omega}_{t}$ with $\boldsymbol{\Omega}_{t}=\mathbf{P}_{t} \mathbf{P}_{t}^{\prime}$ is possible. The structure $\mathbf{B}_{t}^{-1} \boldsymbol{\Sigma}_{t}$ is common in the literature on the efficient estimation of covariance matrices (e.g. Pourahmadi, 1999, 2000; Smith and Kohn, 2002). It is only chosen to facilitate estimation.
} 
rather evolves slowly over the decades.

The prior choices can be summarized as

$$
\begin{aligned}
\mathbf{a}_{0} & \sim N\left(\hat{\mathbf{a}}^{O L S}, 4 \operatorname{Var}\left(\hat{\mathbf{a}}^{O L S}\right)\right) \\
\mathbf{b}_{0} & \sim N\left(\hat{\mathbf{b}}^{O L S}, k^{2} \mathbf{I}_{3}\right) \\
\log \boldsymbol{\sigma}_{0} & \sim N\left(\log \boldsymbol{\sigma}^{O L S}, k \mathbf{I}_{n}\right) \\
\mathbf{Q} & \sim I W\left(k^{2} 80 \operatorname{Var}\left(\hat{\mathbf{a}}^{O L S}\right), 80\right) \\
\mathbf{W} & \sim I W\left(k^{2} 400 \mathbf{I}_{n}, 400\right) \\
\mathbf{S}_{1} & \sim I W\left(k^{2} 21 \mathbf{I}_{1}, 21\right) \\
\mathbf{S}_{2} & \sim I W\left(k^{2} 22 \mathbf{I}_{2}, 22\right)
\end{aligned}
$$

where $k$ is a scaling factor that is set to 0.01 .

\section{$5 \quad$ Empirical Results}

The Gibbs sampling algorithm described in Primiceri (2005) is used to generate 30000 draws from the posterior, discarding the first 9000 as burn-in. More details about the sampling algorithm are presented in the appendix. All convergence diagnostics conducted were satisfactory.

To obtain a parsimonious specification, we choose a lag order of one. This is similar to Reichmuth (2008) and Nicolini (2007) who find one to two lags to be appropriate. ${ }^{10}$

Since the crude death series contains some massive spikes caused primarily by epidemics and wars, we also experimented with dummies similar to Nicolini (2007). As the results were not changed when including the dummies only the results without dummies are shown.

\footnotetext{
${ }^{10}$ This parsimonious specification is necessary as the computations involved are very burdensome. An increase in dimensionality quickly makes estimation infeasible.
} 
In the following we present the empirical results. The time-variation of the variances is discussed first. Then the three (short-run) implications of the Malthusian model are explored using impulse response analysis. We examine the existence of positive and preventive checks as well as the reaction of wages to population changes in the period from 1600 to 1870 . In contrast to earlier studies, we do not have to rely on sub-samples because our approach enables computing impulse responses for each year.

\subsection{Declining Volatilities}

We start the analysis by investigating the estimated volatilities. The posterior means for the standard deviations of the structural shocks in the period from 1600 to 1870 are displayed in Figure 2. A clear decline in all variances is visible over the centuries, which is most pronounced in the mortality series and least pronounced in the real wage series. Given the rather tight priors on changes in volatilities, this result clearly indicates the importance of heteroscedastic errors terms.

The results are similar to the observation of Wrigley and Schofield (1981). According to the authors, the amplitude of decadal fluctuations around a 25-year moving average in the demographic series declined over time, and variations in the mortality series always used to be more pronounced than in fertility (Wrigley and Schofield, 1981, pp. 313-320). ${ }^{11}$ Moreover, it is well known that major surges in mortality due to epidemic diseases or starvation disappeared. Contrary to Wrigley and Schofield, the variability in the error term of the wage series declines weakly until mid-18th century and stays constant afterwards. Using the Phelps Brown and Hopkins (1956) real wage series, they conclude that the variability in real wages declined up to 1790 and increased afterwards. 
Figure 2: Estimated Volatilities

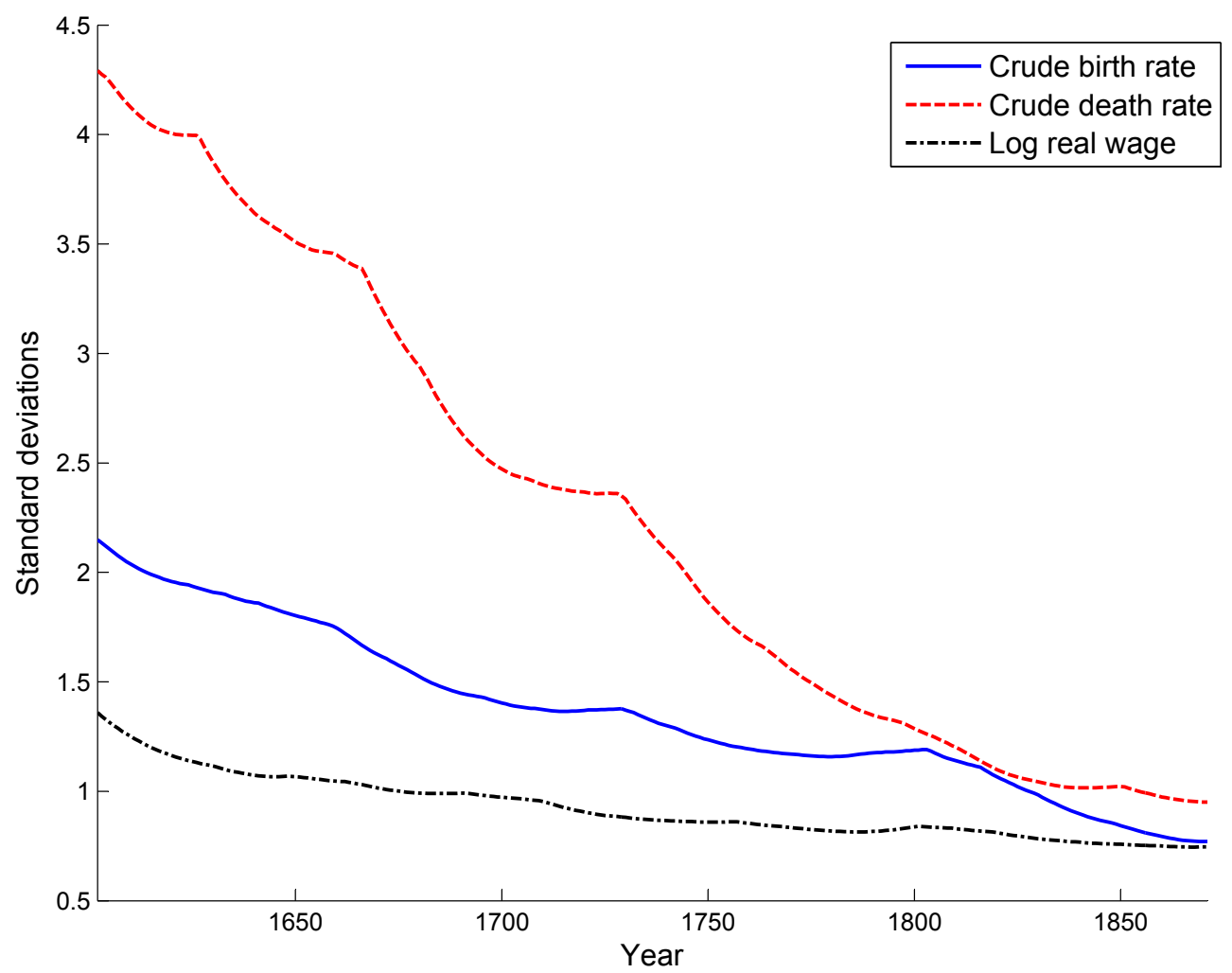

Notes: The graph shows posterior means of the estimated standard deviation of the structural shocks. For clearer presentation the standard deviation of the real wage shock was rescaled by a factor of 15 .

\subsection{Preventive Check}

First, we turn to the reaction of fertility to changes in the wage rate. The preventive check implies a positive relationship between real wages and fertility. Figure 3 shows posterior means of the impulse responses of the crude birth rate to real wage shocks over time. Each graph displays the impulse response to a wage shock after a specific number of years, calculated for each decade from 1600 to 1870 . The upper-left graph depicts the instantaneous responses of the birth rate to a wage shock. The impulse responses at impact

\footnotetext{
${ }^{11}$ The declining volatility was also noted by Nicolini (2007) and Reichmuth (2008).
} 
Figure 3: Response of $C B R$ to a wage shock, 1600-1870.
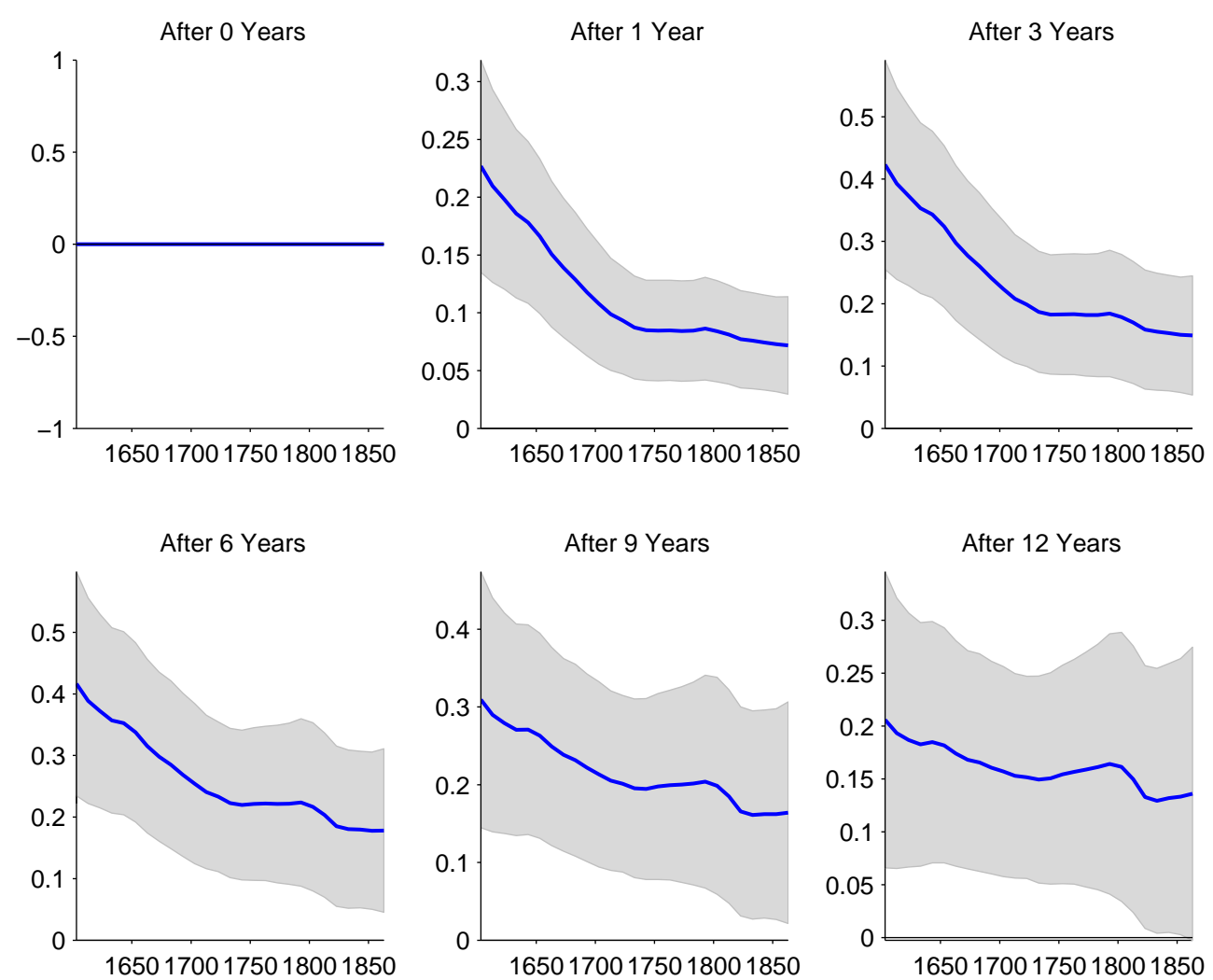

Notes: Posterior means of the impulse response to a one unit shock to the real wage after a specified number of years for each decade from 1600 to 1870 . The gray area indicates the 16 th and 84 th percentiles of the impulse responses.

are equal to zero for all time periods, which follow directly from our identification strategy. However, this changes in the first year after the shock. The graph in the upper middle panel clearly reveals a positive effect of a wage shock on fertility which is particularly strong in the 17th century. The impulse responses are positive and hump shaped for each point in time. In each decade the impact first becomes stronger (after three and six years) and then starts to decay again (after nine and twelve years). Overall, the relationship between real wages and the birth rate becomes weaker until the 1730s. In the following decades the strictness of the preventive check stays constant until the beginning of the 19th century when it starts to decline again slightly. 
Figure 4: Accumulated Impulse Responses, 1600-1870.
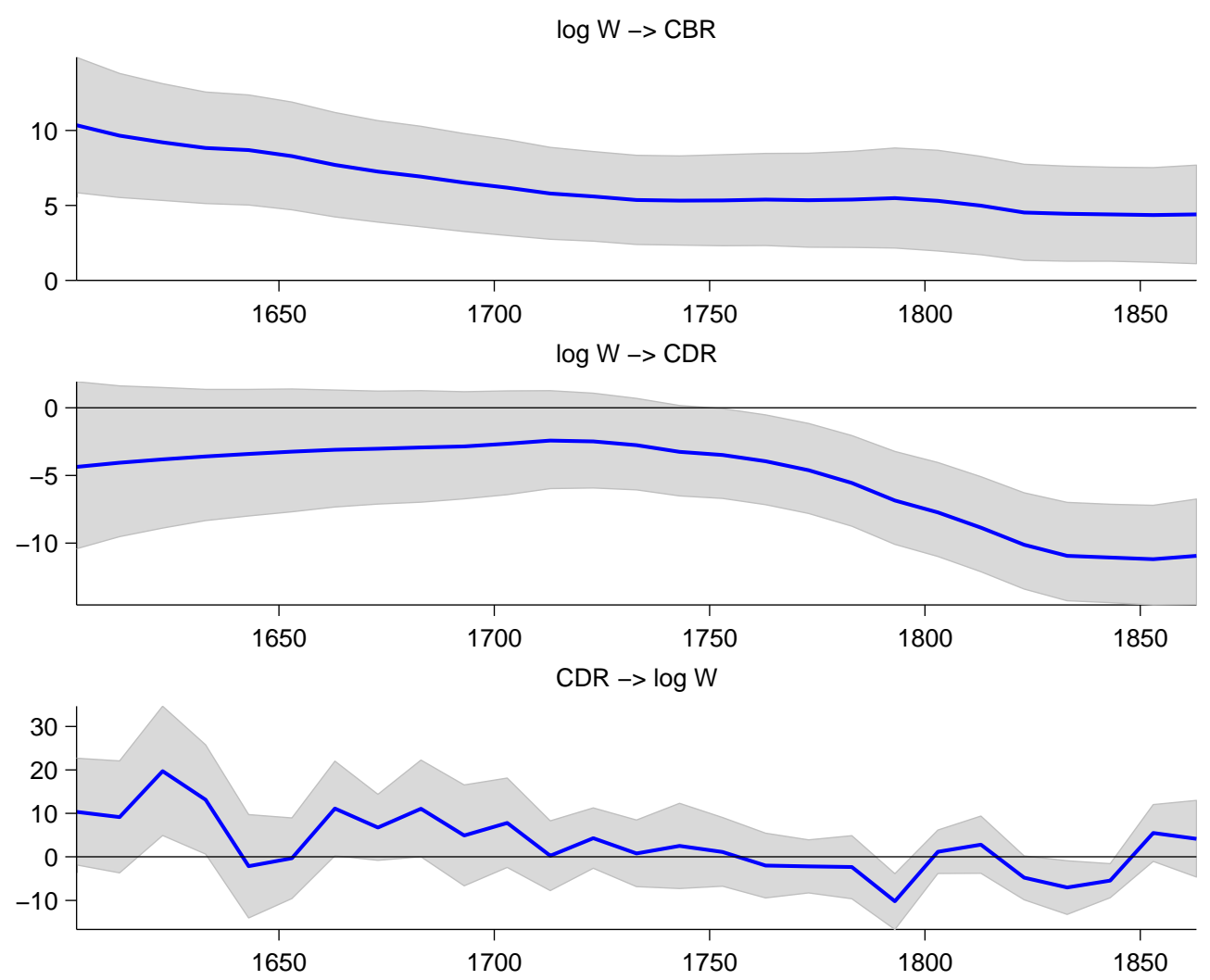

Notes: Posterior means of the accumulated impulse response after ten years for each decade from 1600 to 1870 . The gray area indicates the 16 th and 84 th percentiles of the impulse responses.

To assess the overall impact, the uppermost panel of Figure 4 shows the accumulated impulse response after ten years for each decade from 1600 to 1870 expressed in percentage terms of the average birth rate. It reveals that the accumulated response to a wage shock declines from a 10 percent change in fertility in 1550 to a 5 percent change in the first half of the 18th century and then remains stable until the turn of the century. After that, a rather small decline in the accumulated response can be observed again.

Like Wrigley and Schofield (1981), Lee (1981), and Galloway (1988), we 
Figure 5: Response of $C D R$ to a wage shock, 1600-1870.
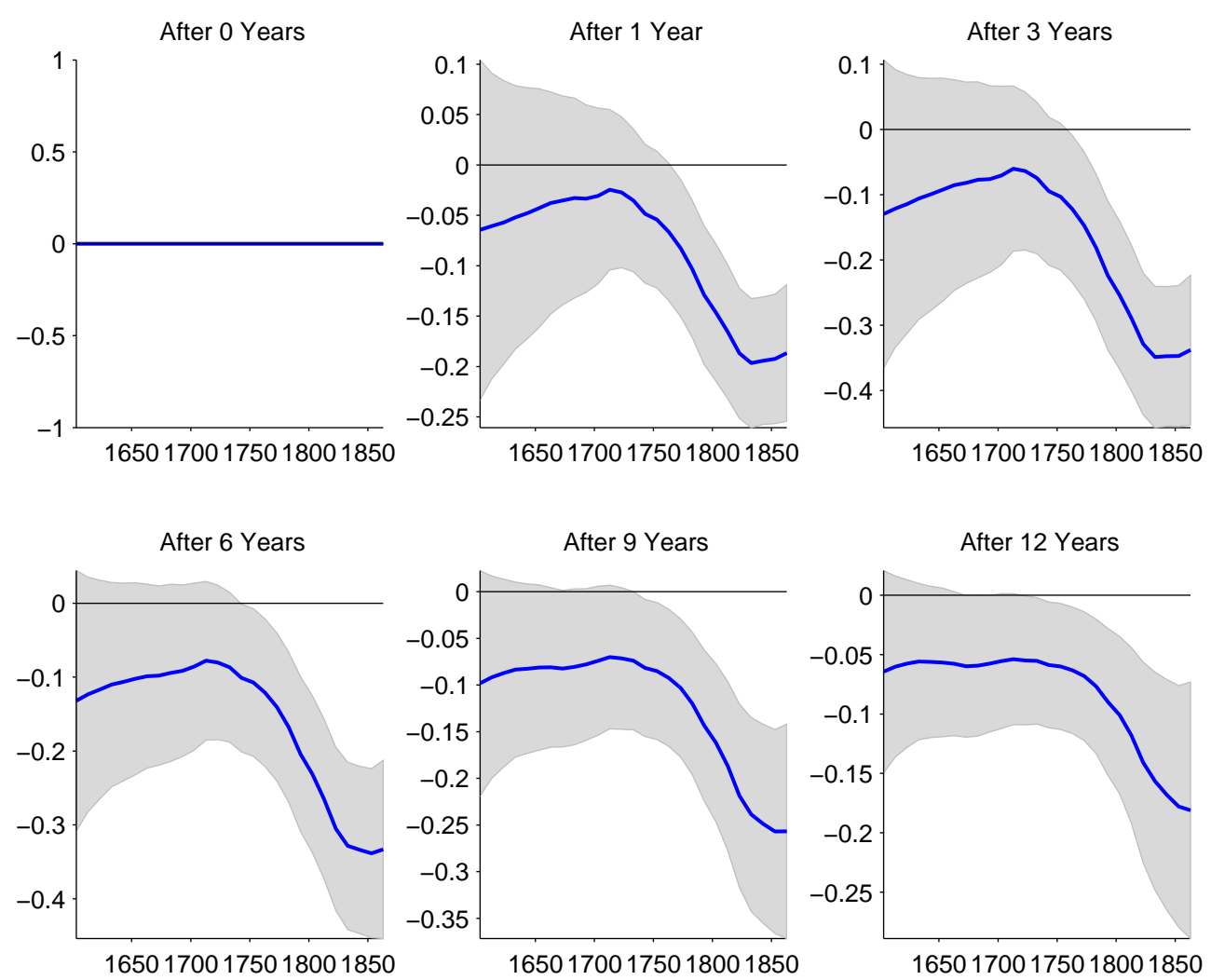

Notes: Posterior means of the impulse response to a one unit shock to the real wage after a specified number of years for each decade from 1600 to 1870 . The gray area indicate the 16 th and 84th percentiles of the impulse responses.

find evidence of the existence of a Malthusian preventive check, although it became less strict over time. These results differ substantially from those of Nicolini (2007) and Crafts and Mills (2009). They find the preventive check for sub-samples including data up to the mid-18th century, but no evidence of the existence afterwards. Nicolini's results even point to a negative relationship between real wages and fertility in the period between 1741 and 1840 , which is a characteristic feature of modern demographic patterns.

Apart from affecting fertility through nutrition, frequency of intercourse, proportion of anovulatory menstrual cycles and foetal wastage, the positive 
effect of real wages on fertility mainly acted via an increase in marriages (Wrigley and Schofield, 1981, Chapter 8). ${ }^{12}$ Interestingly, the end of the decline in the effectiveness of the preventive check roughly coincides with the breakdown of the European Marriage Pattern (EMP) at the beginning of the 18th century, which combined late marriage or celibacy with unrestricted fertility within marriage (Hajnal, 1965). ${ }^{13}$ As a result, fertility increased due to earlier marriage in the 18th century (Wrigley et al., 1997). In this particular period, fertility was starting to become detached from variations in wages. One reason could be that illegitimate and prenuptial births increased during that time. Voigtländer and Voth (2009a) also argue that the vanishing of late marriage might be explained by the decline in employment opportunities for women in husbandry.

\subsection{Positive Check}

Figure 5 shows the estimation results for the relationship between real wages and mortality. The positive check implies that a decline in real wages should be associated with an increase in mortality. This negative effect can be found throughout the entire sample. While the effect is mild in the beginning of the sample, it starts growing stronger in the mid-18th century, reaching its trough at 1850. It can also be observed that the effects are decaying slowly and are still alive after twelve years (second row of Figure 5). This implies a relatively persistent wage shock. The second row of Figure 4 displays the accumulated impulse responses. As can be seen, the impact on mortality after ten years is about 5 percent until the mid-of the 18th century. The effect doubles to 10 percent by the mid-19th century.

These findings are different from e.g. Lee and Anderson (2002) and Møller

\footnotetext{
${ }^{12}$ See also Clark (2007, Chapter 4). However, Lee (1975) cannot find supportive evidence.

${ }^{13}$ Postponing or eschewing marriage could limit fertility to less than half the biological maximum (Clark, 2007). Voigtländer and Voth (2009a,b) explain the formation of the EMP as an endogenous response to a large income shock caused by the black death, which caused a major change in the structure of agricultural production from "corn to horn" resulting in more employment opportunities for women as servants in animal husbandry.
} 
and Sharp (2008), who do not find any indication of the positive check at all. It also differs from Nicolini (2007) and Crafts and Mills (2009), who cannot identify the positive check after 1640. The same is true for Wrigley and Schofield (1981) and Lee (1981) who found that the positive check disappeared sometime in the early 17th century. In contrast, we find that the positive check was still active around 1750 and did not vanish afterwards. Astonishingly, the strongest relationship between real wages and mortality existed during the period of 1750-1850, where it is commonly supposed not to hold.

The appearance of the positive check during the period of the industrial revolution might be explained by the rapid urbanization during the beginning of the industrial revolution. Industrialization and urbanization created insanitary and dangerous living conditions, leading to a higher sensitivity of mortality to real wages for a large part of the population. ${ }^{14}$ The rapid growth of towns and industrial areas, as well as the corresponding side effects, such as overcrowding, an increase in crime, inadequate access to sanitation and other infrastructure, inadequate access to safe water and poor quality of working-class housing are among the proposed explanations. In addition, the agricultural labor share decreased from 35 percent in 1801 to 22 percent in 1851, while the industrial labor share increased from 29 percent to 42 percent. ${ }^{15}$ This shift from the primary to the secondary sector indicates that the share of wage earners in the labor force increased. The combination of higher mortality in the cities and the increasing importance of wage-related income therefore is a possible explanation for the intensified relationship between real wages and mortality during the period of 1750-1850.

\footnotetext{
${ }^{14}$ There is a large literature on this phenomenon, see for example Hobsbawm (1962, Chapter 11), Lindert (1994, Chapter 14), and Voth (2004, Chapter 10). Compared to the rest of England Kelly and Ó Gráda (2009) find a stronger positive check when using data for London only.

${ }^{15}$ See Deane and Cole $(1969$, p. 143). The share of the agricultural sector in total output almost halved from around 40 percent in 1790 to 21 percent in 1850, whereas the share of the industrial sector almost doubled from around 21 percent in 1790 to 35 percent in 1850 (Mitchell, 2003, p. 934).
} 
Our estimates also are very much in line with evidence found in the biological standard of living literature, where human stature is used to measure economic status. This proxy measure declines in the early stages of the industrial revolution. ${ }^{16}$ Komlos (1998) refers to this phenomenon as "early-industrialgrowth puzzle". He argues that industrialization was accompanied beside urbanization by higher frequency of unemployment and income inequality. The result was that economic progress unequally impinged on human wellbeing. For some parts of the population living conditions even deteriorated in some respects. "The human organism did not always thrive as well in its newly created socioeconomic environment as one might be led to believe on the basis of purchasing power at the aggregate level" (Komlos, 1998, p. 793).

\section{$5.4 \quad$ Feedback Effect}

We next turn to the feedback effect of population on wages. The Malthusian theory predicts that real wages should decline with an increase in population. ${ }^{17}$ Figure 6 depicts the effect of short-run variations in the death rate on real wages. Considering the impact of a mortality shock at impact (after 0 years), a sharp increase in real wages can be observed in the beginning of the 17th century. Around the time of the English civil war (1641-1651), the feedback effect vanishes and then re-emerges in the remaining years of the 17th century, albeit not as strongly as before. Afterwards, the feedback effect begins to disappear slowly over time. Since the impulse responses decay steadily over time for all decades, a similar pattern is evident in all graphs, as well as in the lower panel of Figure 4, which shows the accumulated effects. The size of the estimated accumulated feedback effect in the 17th century (excluding the war) is considerable. The mean wage increase after a decade could reach up to 20 percent. The aggregate effect then declines and becomes negligible in the 18th century.

\footnotetext{
${ }^{16}$ See, e.g. Komlos $(1993,1998)$, Nicholas and Steckel (1991), Johnson and Nicholas (1995), and Floud et al. (1990).

${ }^{17}$ Due to a higher dimensionality of the resulting system and identification problems we could not include population into our framework. See Lee (1987, 1993), and Lee and Anderson (2002) for an analysis of the direct link between population and wages.
} 
Figure 6: Response of real wage to a $C D R$ shock, 1600-1870.
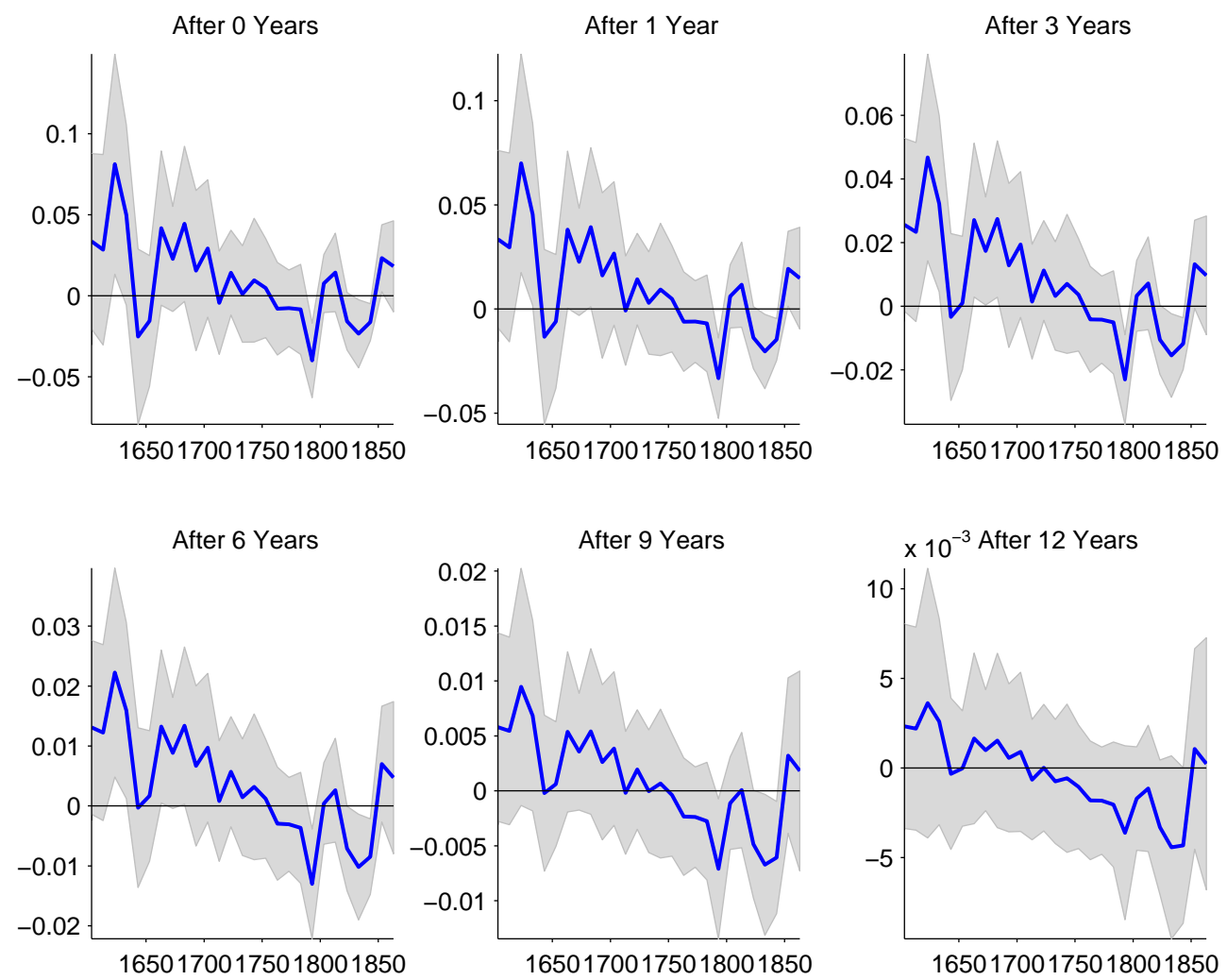

Notes: Posterior means of the impulse response of the real wage to a one unit shock to the death rate after a specified number of years for each decade from 1600 to 1870. The gray area indicate the 16 th and 84 th percentiles of the impulse responses.

Thus, the results confirm that there was a positive effect of a smaller labor force on the real wage rate (e.g. Lee, 1973; Lee and Anderson, 2002) at least for the time up to the eighteenth century. This early breakdown is also similar to the findings of Nicolini (2007).

When interpreting these results, some caveats apply. Although an increase in the death rate reduces population, it does not necessarily imply that the workforce is also decreasing. It might also be the case that only the mortality of infants experience an upsurge, which implies a very delayed impact 
on labor supply. Furthermore, due to shifts in women's participation rates or migration, the relevant labor supply might stay constant or even increase. This can cause the impulse response to change the sign for short periods from late 18th century on. The strongest dip of the accumulated response in Figure 4 in the last few decades of the 18th century corresponds to the highest peak in net population inflow, (Wrigley and Schofield, 1981, pp. 219-220).

For the sake of completeness, we would like to add that we find a negative effect of a fertility shock on mortality, which is surprising as child mortality is high in the period under analysis. The same result was found by Nicolini (2007). Mortality shocks have a positive effect on fertility, which is probably due to the replacement motive after child $\operatorname{loss}^{18}$ or the availability of more vacant farm and craft practices, which promised the resources needed to embark on the enterprise of marriage (Wrigley and Schofield, 1981, p. 402).

\section{Conclusion}

Testing the Malthusian hypothesis is a challenging task. On the one hand, studying such an equilibrating system always involves issues concerning endogeneity. On the other hand, the data usually used span several centuries mostly including the transition from a stagnating to an industrialized economy. Hence, time variation of the relationship between the variables and their variances poses serious problems.

This paper documented changes in the interaction of vital rates and real wages in the period from 1540 to 1870 in England. The time-varying VAR approach takes the endogeneity of the variables and the drifts and volatilities contained in the data into account. Hence, the potential shortcomings of the previous literature, which disproved the Malthusian framework in the period between 1740 and 1870, are overcome.

\footnotetext{
${ }^{18}$ The birth interval was shortened by over eight months in case of infant death (Wrigley et al., 1997, p. 351).
} 
The results indicate the importance of time variation. The apparent decline of volatility in the birth and death rate series is confirmed by the calculations of the stochastic volatilities. We find that the main Malthusian mechanisms - the preventive and the positive check - were both at work until the mid19th century. The preventive check was decreasing and the positive check increasing in importance. Previous econometric analysis of the Malthusian framework, where the existence of the Malthusian model after the mid-18th century is challenged, are clearly contradicted by our results. In particular, the preventive check can be observed in early 19th Century England even though the impact has halved over the past two centuries. The positive check was most strictly enforced after the 1750s. This result on the relationship between real wages and mortality differs substantially from other econometric studies. However, it is in line with historical evidence as well as findings in the biological standard of living literature. Instead of disappearing before the advent of the industrial revolution, the Malthusian mechanism rather changed its face over time. 


\section{References}

Allen, Robert C., "The Great Divergence in European Wages and Prices from the Middle Ages to the First World War," Explorations in Economic History, October 2001, 38 (4), 411-447.

Artzrouni, Marc and John Komlos, "Population Growth Through History and the Escape from the Malthusian Trap: A Homeostatic Simulation Model," Genus, 1985, 41, 21-39.

Ashraf, Quamrul and Oded Galor, "Dynamics and Stagnation in the Malthusain Epoch: Theory and Evidence," Working Papers 2008-14, Brown University, Department of Economics 2008.

Bongaarts, John, "A Framework for Analyzing the Proximate Determinants of Fertility," Population and Development Review, 1978, 4, 105-132.

Broadberry, Stephen, "Recent Developments in the Theory of Very Long Run Growth: A Historical Appraisal," The Warwick Economics Research Paper Series (TWERPS) 818, University of Warwick, Department of Economics 2007.

Carter, C. K. and R. Kohn, "On Gibbs Sampling for State Space Models," Biometrika, 1994, 81, 541-553.

Cervellati, Matteo and Uwe Sunde, "Human Capital Formation, Life Expectancy, and the Process of Development," American Economic Review, December 2005, 95 (5), 1653-1672.

_ and _, "Health, Development, and the Demographic Transition," 2006 Meeting Papers 645, Society for Economic Dynamics December 2006.

Clark, Gregory, "The Condition of the Working Class in England, 12092004," Journal of Political Economy, December 2005, 113 (6), 1307-1340.

_, A Farewell to Alms: A Brief Economic History of the World, Princeton, NJ: Princeton University Press, 2007. 
Cogley, Timothy and Thomas J. Sargent, "Drift and Volatilities: Monetary Policies and Outcomes in the Post WWII U.S," Review of Economic Dynamics, April 2005, 8 (2), 262-302.

Crafts, Nicholas and Terence C. Mills, "From Malthus to Solow: How Did the Malthusian Economy Really Evolve?," Journal of Macroeconomics, March 2009, 31 (1), 68-93.

Deane, Phyllis and W. A. Cole, British Economic Growth 1688-1959, 2nd ed., Cambridge University Press, 1969.

Floud, Roderick, Kenneth Wachter, and Annabel Gregory, Height, Health and History: Nutritional Status in the United Kingdom, 1750-1980, Cambridge: Cambridge University Press, 1990.

Fuller, Wayne A., Introduction to Statistical Time Series, NJ: John Wiley \& Sons, Inc., 1996.

Galloway, Patrick R., "Basic Patterns in Annual Variations in Fertility, Nupiality, Mortality, and Prices in Pre-Industrial Europe," Population Studies, 1988, 42, 275-303.

Galor, Oded, "From Stagnation to Growth: Unified Growth Theory," in Aghion. Philippe and Steven N. Durlauf, eds., Handbook of Economic Growth 1A, Vol. 1A, Elsevier B. V., 2005, chapter 4, pp. 171-292.

_ , "2008 Lawrence R. Klein Lecture - Comparative Economic Development: Insights from Unified Growth Theory," Working Papers 2009-10, Brown University, Department of Economics 2009.

- and David N. Weil, "Population, Technology, and Growth: From Malthusian Stagnation to Demographic Transition and Beyond," American Economic Review, 2000, 90, 806-828.

- and Omer Moav, "Natural Selection and the Origin of Economic Growth," The Quarterly Journal of Economics, November 2002, 117 (4), 1133-1191. 
Hajnal, John, "European Marriage Pattern in Historical Perspective," in D V Glass and D E Eversley, eds., Population in History: Essays in Historical Demography, Chicago: Aldine Publishing Company, 1965, pp. 101143.

Hansen, Gary and Edward Prescott, "Malthus to Solow," American Economic Review, 2002, 92, 1205-1217.

Hobsbawm, Eric, The Age of Revolution: 1789-1848, London: Weidenfeld and Nicolson, 1962.

Johnson, Paul and Stephen Nicholas, "Male and Female Living Standards in England and Wales, 1812-1857: Evidence From Criminal Height Records," The Economic History Review, 1995, 48, 470-481.

Jones, Charles, "Was an Industrial Revolution Inevitable? Economic Growth Over the Very Long Run," Advances in Macroeconomics, 2001, $1,1028-1028$.

Kelly, Morgan and Cormac Ó Gráda, "Living Standards and Mortality in England Since the Middle Ages," mimeo, University of Dublin 2009.

Kim, S., N. Shephard, and S. Chib, "Stochastic Volatility: Likelihood Inference and Comparison with ARCH Models," Review of Economic Studies, 1998, 65, 361-393.

Komlos, John, "The Secular Trend in the Biological Standard of Living in the United Kingdom, 1730-1860," The Economic History Review, 1993, 46, 115-144.

_ , "Shrinking in a Growing Economy? The Mystery of Physical Stature during the Industrial Revolution," The Journal of Economic History, September 1998, 58 (03), 779-802.

- and Marc Artzrouni, "Mathematical Investigations of the Escape from the Malthusian Trap," Mathematical Population Studies, 1990, 2, 269-287. 
Kremer, Michael, "Population Growth and Technological Change: One Million B.C. To 1990," Quarterly Journal of Economics, 1993, 108, 681716.

Lagerlöf, Nils-Petter, "From Malthus to Modern Growth: Can Epidemics Explain the Three Regimes?," International Economic Review, 2003, 44, $755-777$.

_ , "The Galor-Weil Model Revisited: A Quantitative Exercise," Review of Economic Dynamics, January 2006, 9 (1), 116-142.

Lee, Ronald D., "Population in Preindustrial England: An Econometric Analysis," The Quarterly Journal of Economics, 1973, 87 (4), 581-607.

_, "Natural Fertility, Population Cycles and the Spectral Analysis of Births and Marriages," Journal of the American Statistical Association, 1975, 70 (350), 295-304.

_ , "Short Term Variation: Vital Rates, Prices and Weather," in Edward A. Wrigley and Roger S. Schofield, eds., The Population History of England, 1541-1871: A Reconstruction, London: Edward Arnold, 1981, pp. 285-355.

_ , "Population Dynamics of Humans and Other Animals," Demography, 1987, 24 (4), 443-465.

_, "Accidental and Systematic Change in Population History: Homeostasis in a Stochastic Setting," Explorations in Economic History, 1993, 30 (1), $1-30$.

- and Michael Anderson, "Malthus in State Space: Macro EconomicDemographic Relations in English History, 1540 to 1870," Journal of Population Economics, 2002, 15 (2), 195-220.

Lindert, Peter H., "Unequal Living Standards," in Roderick Floud and Donald McCloskey, eds., The Economic History of Britain Since 1700: 1700-1860, Vol. 1, Cambridge: Cambridge University Press, 1994, pp. 357386. 
Lucas, Robert E., "The Industrial Revolution: Past and Future," in "Lectures on Economic Growth," Cambridge, Massachusetts, and London, England: Harvard University Press, 2002, pp. 109-188.

Malthus, Thomas Robert, An Essay on the Principle of Population, St. Paul's Church-Yard, London: J. Johnson, 1798.

Mitchell, Brian R., International Historical Statistics: Europe 1750-1975, NY: Palgrave Macmillan, 2003.

Mokyr, Joel and Hans-Joachim Voth, "Understanding Growth in Europe, 1700-1870: Theory and Evidence," mimeo 2007.

Møller, Niels F. and Paul Sharp, "Malthus in Cointegration Space: A New Look at Living Standards and Population in Pre-Industrial England," Discussion Papers 08-16, University of Copenhagen. Department of Economics 2008.

Nicholas, Stephen and Richard H. Steckel, "Heights and Living Standards of English Workers During the Early Years of Industrialization, 1770-1815," Journal of Economic History, 1991, 51, 937-957.

Nicolini, Esteban A., "Was Malthus Right? A Var Analysis of Economic and Demographic Interactions in Pre-Industrial England," European Review of Economic History, 2007, 11, 99-121.

Phelps Brown, Ernest H. and Sheila V. Hopkins, "Seven Centuries of the Prices of Consumables, Compared with Builders' Wage- Rates," Economica, 1956, 23, 296-314.

Pourahmadi, Mohsen, "Joint Mean-Covariance Models with Applications to Longitudinal Data: Unconstrained Parameterisation," Biometrika, 1999, 86 (3), 677-690.

_ , "Maximum Likelihood Estimation of Generalised Linear Models for Multivariate Normal Covariance Matrix," Biometrika, 2000, 87 (2), 425-435. 
Primiceri, Giorgio E., "Time Varying Structural Vector Autoregressions and Monetary Policy," Review of Economic Studies, 2005, 72, 821-852.

Reichmuth, Wolfgang, "Malthus in the Nordic Countries ? A Bayesian VAR Analysis of Economic-Demographic Interactions in the 18th and 19th Century," 2008. Humbolt-University Berlin, mimeo.

Smith, Michael S. and Robert J. Kohn, "Parsimonious Covariance Matrix Estimation for Longitudinal Data," Journal of the American Statistical Association, December 2002, 97, 1141-1153.

Tamura, Robert, "Human Capital and the Switch from Agriculture to Industry," Journal of Economic Dynamics and Control, 2002, 27, 207-242.

Voigtländer, Nico and Hans-Joachim Voth, "How the West Invented Fertility Restrictions," mimeo, UCLA Anderson School of Management 2009 .

_ and _ , "Malthusian Dynamics and the Rise of Europe: Make War, Not Love," American Economic Review: Papers $\&$ and Proceedings, 2009, 99, $248-254$.

Voth, Hans-Joachim, "Living Standards and the Urban Environment," in Roderick Floud and Paul Johnson, eds., The Cambridge Economic History of Modern Britain: Industrialisation, 1700-1860, Vol. 1, Cambridge: Cambridge University Press, 2004, pp. 268-294.

Wrigley, Edward A. and Roger S. Schofield, The Population History of England, 1541-1871: A Reconstruction, London: Edward Arnold, 1981.

_ , R. S. Davis, James E. Oeppen, and Roger S. Schofield, English Population History from Family Reconstitution 1580-1837, Cambridge: Cambridge University Press, 1997. 


\section{A Appendix}

\section{A.1 Overview over the Gibbs Sampling Procedure}

The distribution of the posterior can be evaluated using MCMC methods. The Gibbs sampler allows to generate draws from the posterior by iteratively drawing from a full set of conditional distributions. The following gives first an overview over the whole Gibbs sampling procedure and then describes the respective steps in more detail.

\section{A.1.1 Overview over the Gibbs Sampler}

The Gibbs sampling involves the following steps

I Initialize $\mathbf{b}^{T}, \boldsymbol{\Sigma}^{T}, \mathbf{s}^{T}, \mathbf{V}$

II Sample $\mathbf{a}^{T}$ from $p\left(\mathbf{a}^{T} \mid \mathbf{y}^{T}, \mathbf{x}^{T}, \mathbf{b}^{T}, \mathbf{\Sigma}^{T}, \mathbf{V}\right)$.

III Sample $\mathbf{b}^{T}$ from $p\left(\mathbf{b}^{T} \mid \mathbf{y}^{T}, \mathbf{x}^{T}, \mathbf{a}^{T}, \mathbf{\Sigma}^{T}, \mathbf{V}\right)$.

IV Sample $\boldsymbol{\Sigma}^{T}$ from $p\left(\boldsymbol{\Sigma}^{T} \mid \mathbf{y}^{T}, \mathbf{x}^{T}, \mathbf{a}^{T}, \mathbf{b}^{T}, \mathbf{s}^{T}, \mathbf{V}\right)$.

V Sample $\mathbf{s}^{T}$ from $p\left(\mathbf{s}^{T} \mid \mathbf{y}^{T}, \mathbf{x}^{T}, \mathbf{a}^{T}, \mathbf{b}^{T}, \mathbf{V}\right)$.

VI Sample $\mathbf{V}$, by sampling $\mathbf{Q}, \mathbf{W}$ and $\mathbf{S}$ from $p\left(\mathbf{Q}, \mathbf{W}, \mathbf{S} \mid \mathbf{y}^{T}, \mathbf{x}^{T}, \mathbf{A}^{T}, \mathbf{B}^{T}, \mathbf{\Sigma}^{T}\right)=$ $p\left(\mathbf{Q} \mid \mathbf{y}^{T}, \mathbf{x}^{T}, \mathbf{A}^{T}, \mathbf{B}^{T}, \mathbf{\Sigma}^{T}\right) p\left(\mathbf{W} \mid \mathbf{y}^{T}, \mathbf{x}^{T}, \mathbf{A}^{T}, \mathbf{B}^{T}, \boldsymbol{\Sigma}^{T}\right) \ldots$ $p\left(\mathbf{S}_{1} \mid \mathbf{y}^{T}, \mathbf{x}^{T}, \mathbf{A}^{T}, \mathbf{B}^{T}, \mathbf{\Sigma}^{T}\right) p\left(\mathbf{S}_{n-1} \mid \mathbf{y}^{T}, \mathbf{x}^{T}, \mathbf{A}^{T}, \mathbf{B}^{T}, \mathbf{\Sigma}^{T}\right)$

VII Go back to II.

\section{A.1.2 Step II: Drawing VAR parameters $\mathbf{a}^{T}$}

For given $\mathbf{b}^{T}, \boldsymbol{\Sigma}^{T}$ and $\mathbf{V}$, equations (3) together with (4) constitute the following linear Gaussian state-space system:

$$
\begin{aligned}
& \mathbf{y}_{t}=\left(\mathbf{Z}_{t-1}^{\prime} \otimes \mathbf{I}_{n}\right) \mathbf{a}_{t}+\mathbf{u}_{t}, \\
& \mathbf{a}_{t}=\mathbf{a}_{t-1}+\boldsymbol{\nu}_{t}
\end{aligned}
$$


Therefore, the sampling procedure of Carter and Kohn (1994) can be applied to generate $\mathbf{a}^{T}$.

\section{A.1.3 Step III: Drawing covariance states $b^{T}$}

For a given $\mathbf{a}^{T}$, it is possible to observe $\hat{\mathbf{y}}_{t}$, which is defined as

$$
\hat{\mathbf{y}}_{t}=\mathbf{y}_{t}-\left(\mathbf{Z}_{t-1}^{\prime} \otimes \mathbf{I}_{n}\right) \mathbf{a}_{t}
$$

Note that (3) can be expressed as

$$
\mathbf{B}_{t} \hat{\mathbf{y}}_{t}=\boldsymbol{\Sigma}_{t} \boldsymbol{\epsilon}_{t}
$$

Due to the diagonal structure of $\mathbf{B}_{t}$ with ones on the main diagonal, the left hand-side of (7) can be written as $\hat{\mathbf{y}}_{t}+\tilde{\mathbf{L}}_{t} \mathbf{b}_{t}$, where $\tilde{\mathbf{L}}_{t}$ is given by

$$
\left(\begin{array}{ccccccc}
0 & \cdots & \cdots & & 0 & \\
\hat{y}_{1, t} & 0 & \ldots & \vdots & \\
0 & \left(\hat{y}_{1, t}\right. & \left.\hat{y}_{2, t}\right) & \ddots & & \vdots & \\
\vdots & \ddots & \ddots & & 0 & \\
0 & \ldots & 0 & \left(\hat{y}_{1, t}\right. & \hat{y}_{2, t} & \ldots & \left.\hat{y}_{n, t}\right)
\end{array}\right) .
$$

Therefore, the system of equations (7) can be rewritten as

$$
\hat{\mathbf{y}}_{t}=\mathbf{L}_{t} \mathbf{b}_{t}+\boldsymbol{\Sigma}_{t} \boldsymbol{\epsilon}_{t}
$$

where $\mathbf{L}_{t}=-\tilde{\mathbf{L}}_{t}$. Together with $\mathbf{b}_{t}=\mathbf{b}_{t-1}+\boldsymbol{\xi}_{t}$ this system has a state-space representation of this system that is Gaussian, but nonlinear since some of the dependent variables in the measurement equation also appear on the right-hand side. Because of the block diagonal structure of $\mathbf{S}$, this problem can easily be solved by applying the sampling procedure of Carter and Kohn (1994) equation by equation, starting with the second equation. Note that in that case all variables appearing on the right-hand side of the $i$ th equation include only $\hat{y}_{k, t}, k<i$ which can be treated as predetermined due to the triangular structure. 


\section{A.1.4 Steps IV and V: Drawing volatility states}

Taking $\mathbf{B}^{T}$ and $\mathbf{a}^{T}$ as given, it is possible to observe $\mathbf{y}_{t}^{*}$, which is defined as

$$
\mathbf{y}_{t}^{*}=\mathbf{B}_{t}\left(\mathbf{y}_{t}-\left(\mathbf{Z}_{t-1}^{\prime} \otimes \mathbf{I}_{n}\right) \mathbf{a}_{t}\right)=\boldsymbol{\Sigma}_{t} \boldsymbol{\epsilon}_{t}
$$

This is a system of nonlinear measurement equations. It can be linearized by squaring and taking logarithms of each equation

$$
\log \left(y_{i, t}^{*}\right)^{2}=2 \log \sigma_{i, t}+\log \epsilon_{i, t}^{2}, \quad i=1, \ldots, n
$$

As $\left(y_{i, t}^{*}\right)^{2}$ can be very small, an offset constant is introduced to make the estimation procedure more robust. This results in the following approximating linear state-space form

$$
\begin{aligned}
\mathbf{y}_{t}^{* *} & =2 \mathbf{h}_{t}+\mathbf{e}_{t}, \\
\mathbf{h}_{t} & =\mathbf{h}_{t-1}+\boldsymbol{\eta}_{t},
\end{aligned}
$$

where $y_{i, t}^{* *}=\log \left[\left(y_{i, t}^{*}\right)^{2}+\bar{c}\right], e_{i, t}=\log \epsilon_{i, t}^{2}, h_{i, t}=\log \sigma_{i, t}$. The offset constant $\bar{c}$ was introduced by Fuller (1996, pp. 494-7) and is set to 0.001. Although the representation is linear, it is not Gaussian, as the innovations in the measurement equation are distributed as $\log \chi(1)^{2}$. Since the covariance matrix of $\boldsymbol{\epsilon}_{t}$ is diagonal, the same is true for the covariance matrix of $\mathbf{e}_{t}$. This means that the Gaussian representation of the system in (9) can be found by approximating each element of $\mathbf{e}_{t}$ by a mixture of normal densities as shown by Kim et al. (1998) for the univariate case. They match a number of moments of the $\log \chi(1)^{2}$ distribution using a mixture of seven normal densities with component probability $q_{j}$, and means $m_{j}$ and variance $v_{j}^{2}, j=1, . ., 7$, as tabulated in Table (1). Hence, each element of $\mathbf{e}_{t}$ can be approximated as

$$
f\left(e_{i t}\right) \approx \sum_{j=1}^{7} q_{j} f_{N}\left(\left(e_{i t} \mid m_{j}-1.2704, v_{j}^{2}\right)\right) .
$$


Table 1: Selection of Mixing Distributions

\begin{tabular}{lcrr}
\hline$\omega$ & $q_{j}=\operatorname{Pr}(\omega=j)$ & $m_{j}$ & $v_{j}^{2}$ \\
\hline 1 & 0.00730 & -10.12999 & 5.79596 \\
2 & 0.10556 & -3.97281 & 2.61369 \\
3 & 0.00002 & -8.56686 & 5.17950 \\
4 & 0.04395 & 2.77786 & 0.16735 \\
5 & 0.34001 & 0.61942 & 0.64009 \\
6 & 0.24566 & 1.79518 & 0.34023 \\
7 & 0.25750 & -1.08819 & 1.26261 \\
\hline Source: Kim et al. (1998) & &
\end{tabular}

Source: Kim et al. (1998).

An alternative way to express this is

$$
\begin{aligned}
e_{i, t} \mid s_{i, t} & =j \sim N\left(m_{j}-1.2704, v_{j}^{2}\right), \\
\operatorname{Pr}\left(s_{i, t}=j\right) & =q_{j},
\end{aligned}
$$

where $\mathbf{s}^{T}=\left[\mathbf{s}_{1}, \ldots, \mathbf{s}_{T}\right]$ is a matrix of unobserved indicator states $s_{i, t} \in 1, \ldots, 7$, selecting at every period which member of the normal distribution mixture is used for the approximation of each element in $\mathbf{e}_{t}$. Using the normal approximation to the $\log \chi(1)^{2}$ innovations transforms the system in (9) in a linear and Gaussian one, making the sampling algorithm of Carter and Kohn (1994) again applicable.

Conditional on $\mathbf{y}^{* * T}$ and the new $\mathbf{h}^{T}$, it is possible to sample the new indicator states $\mathbf{s}^{T}$, to be used in the next sweep. This is done by independently drawing each $s_{i, t}$ from the probability mass function defined by

$$
\operatorname{Pr}\left(s_{i, t}=j \mid y_{i, t}^{* *}, h_{i, t}\right) \propto q_{j} f_{N}\left(y_{i, t}^{* *} \mid 2 h_{i, t}+m_{j}-1.2704, v_{j}^{2}\right)
$$

with $j=1, \ldots, 7, \quad i=1, \ldots, n$, and $t=1, \ldots, T$.

\section{A.1.5 Step VI: Sampling covariances V}

Conditional on $\mathbf{a}^{T}, \mathbf{b}^{T}$ and $\mathbf{h}^{T}$ all innovations in the transition equations $\boldsymbol{\nu}_{t}, \boldsymbol{\xi}_{t}$ and $\boldsymbol{\eta}_{t}$ are observable. With inverse Wishart priors, the conditional 
posteriors of $\mathbf{Q}, \mathbf{W}$ and the diagonal blocks of $\mathbf{S}$ are also inverse Wishart. 